\title{
Métodos de preservação e crescimento de Xanthomonas campestris pv. viticola em meio de cultura variando temperatura, pH e concentração de $\mathrm{NaCl}^{*}$
}

\author{
Ana R. P. Nascimento ${ }^{1 * *}$, Rosa L. R. Mariano ${ }^{2 * * *}$ \& Marco A. S. Gama ${ }^{2}$ \\ ${ }^{1}$ Departamento de Tecnologia e Ciências Sociais, Universidade do Estado da Bahia, CEP 48900-000, Juazeiro, BA, e- \\ mail: arpeixoto@uneb.br, ²Departamento de Agronomia, Área de Fitossanidade, Universidade Federal Rural de \\ Pernambuco, CEP 52171-030, Recife, PE, e-mail: rmariano@truenet.com.br
}

(Aceito para publicação em 17/08/2005)

Autor para correspondência: Ana Rosa Peixoto Nascimento

NASCIMENTO, A.R.P., MARIANO, R.L.R. \& GAMA, M.A.S. Métodos de preservação e crescimento de Xanthomonas campestris pv. viticola em meio de cultura variando temperatura, $\mathrm{pH}$ e concentração de $\mathrm{NaCl}$. Fitopatologia Brasileira 30:650-654. 2005.

\section{RESUMO}

A bactéria fitopatogênica Xanthomonas campestris pv. viticola (Xcv) causa o cancro bacteriano da videira (Vitis vinifera), que ocasiona grandes prejuízos à viticultura no Brasil. Os métodos de dessecação em papel de filtro (DPF), repicagens periódicas (RP), água destilada esterilizada (ADE) e folhas herborizadas (FH) foram utilizados para preservar duas estirpes de Xcv durante 12 meses. As variáveis viabilidade e patogenicidade foram avaliadas mensalmente e estimadas pela obtenção de crescimento bacteriano e área abaixo da curva de incidência da doença (AACID). Tanto o método de DPF como o de ADE propiciaram viabilidade constante de 100\% durante 11 meses e os maiores valores de AACID. No método de RP não houve crescimento das estirpes já aos 30 dias, enquanto que, em FH, Xcv foi isolada até cinco meses. $\mathrm{O}$ crescimento das estirpes de Xcv em meio de cultura líquido variando temperatura $(0,5,10,15,20,25,27,28,29,30$, 35,40 e $\left.45^{\circ} \mathrm{C}\right), \mathrm{pH}(5,0 ; 5,5 ; 6,0 ; 6,5 ; 7,0 ; 7,5 ; 8,0 ; 8,5$ e 9,0) e concentração de $\mathrm{NaCl}(1,2,3,4,5,6$ e $7 \%)$ foi avaliado em fotocolorímetro. $\mathrm{O}$ crescimento de $\mathrm{Xcv}$ foi observado no intervalo de 5 até $35^{\circ} \mathrm{C}$, enquanto que o crescimento ótimo ocorreu de 27 a $29{ }^{\circ} \mathrm{C}$. A Xcv não cresceu a zero e $40{ }^{\circ} \mathrm{C}$. O pH ótimo para o crescimento desta bactéria foi 7,5. O crescimento de Xcv decresceu a partir de 3,0\% de $\mathrm{NaCl}$, com concentração letal de 6,0\%.

Palavras-chave adicionais: videira, cancro bacteriano, Xcv.

\section{ABSTRACT}

Preservation methods and growth of Xanthomonas campestris pv. viticola in culture medium varying temperature, $\mathrm{pH}$ and $\mathrm{NaCl}$ concentration

The phytopathogenic bacterium Xanthomonas campestris pv. viticola (Xcv) induces grapevine (Vitis vinifera) bacterial canker, causing severe losses in Brazil. Four preservation methods [dried paper strips (DPS), periodic transfer (PT), sterile distiled water (SDW) and dried leaves (DL)] were compared for storing two Xcv strains over a 12-month periods. Viability and pathogenicity were evaluated every month and estimated by bacterial growth and area under the disease incidence curve (AUDIC). Both the DPS and SDW methods maintained 100\% of cell viability to and showed higher AUDIC values for 11 months. The PT did not permit growth at 30 days while DL maintained cell viability for up to five months. The growth of two Xcv strains in liquid culture medium at varying temperatures $(0,5,10,15,20,25,27$, $28,29,30,35,40$ and $\left.45^{\circ} \mathrm{C}\right), \mathrm{pH}(5.0 ; 5.5 ; 6.0 ; 6.5 ; 7.0 ; 7.5 ; 8.0 ; 8.5$ and 9.0) and $\mathrm{NaCl}$ concentration $(1,2,3,4,5,6$ and $7 \%$ ) was evaluated with spectrophotometer. The Xcv growth was observed from 5 to $35^{\circ} \mathrm{C}$, with optimum growth from 27 to $29{ }^{\circ} \mathrm{C}$. The $\mathrm{Xcv}$ did not grow at zero and $40{ }^{\circ} \mathrm{C}$. The optimum $\mathrm{pH}$ for Xcv growth was 7.5. The pathogen growth declined from $3.0 \% \mathrm{NaCl}$ and was null at $6.0 \%$.

Additional keywords: grapevine, bacterial canker, Xcv.

No Brasil, o cancro bacteriano foi detectado pela primeira vez em 1998 em videiras (Vitis vinifera L.) no Submédio São Francisco, Nordeste do Brasil, onde tem causado prejuízos em cultivares suscetíveis. A doença é causada pela bactéria Xanthomonas campestris pv. viticola (Nayudu) Dye (Xcv) (Malavolta et al., 1999).

\footnotetext{
*Parte da Tese de Doutorado do primeiro autor. Universidade Federal Rural de Pernambuco (2005).

** Bolsista PICDT/CAPES/UNEB

****Bolsista de Produtividade em Pesquisa do $\mathrm{CNPq}$
}

Culturas bacterianas devem ser preservadas para utilização com fins didáticos e de pesquisa (Mariano \& Assis, 2000). O organismo deve ser mantido vivo pelo maior período possível e por um método que não permita ou minimize a ocorrência de mutações ou de variabilidade quanto à patogenicidade, virulência ou características básicas da cultura original (Romeiro, 2001). Vários métodos são utilizados para preservação de bactérias, tais como: repicagem periódica, preservação por secagem, água destilada esterilizada, preservação em órgãos vegetais infetados, 
dessecação em papel de filtro, congelamento a -20 ou -80 ${ }^{\circ} \mathrm{C}$, óleo mineral, nitrogênio líquido, preservação em solo, contas de vidro ou porcelana e liofilização (Mariano \& Assis, 2005; Romeiro, 2001).

Poucos estudos têm sido conduzidos sobre fatores que afetam o crescimento de Xcv. Segundo Barbosa \& Torres (1999) o metabolismo celular de uma bactéria está diretamente ligado a muitos fatores físicos e químicos do meio ambiente, que interferem na assimilação dos nutrientes a serem utilizados. Para atingir o máximo de desenvolvimento, uma bactéria necessita, entre outros fatores, de condições ideais de temperatura, $\mathrm{pH}$ e concentrações de sais. Segundo Malavolta et al. (1999) e Araujo (2001), estirpes de Xcv crescem até $36{ }^{\circ} \mathrm{C}$, enquanto informações sobre $\mathrm{pH}$ e concentração de sais são inexistentes. Bactérias fitopatogênicas toleram diferentes concentrações de $\mathrm{NaCl}$, sendo este teste bastante utilizado em identificação (Mariano et al., 2005).

Este trabalho objetivou comparar métodos de preservação de Xcv e determinar a influência da temperatura, pH e concentração de $\mathrm{NaCl}$ no crescimento do patógeno, em meio de cultura.

Foram utilizadas as estirpes Xcv1 e UnB1216, ambas obtidas de ramos de videira 'Red Globe' com sintomas característicos do cancro bacteriano, sendo a primeira proveniente de Juazeiro, BA, e a segunda de Petrolina, PE, sendo esta pertencente à Coleção de Bactérias Fitopatogênicas do Departamento de Fitopatologia da Universidade de Brasília, Brasília, DF. A patogenicidade das estirpes foi confirmada pela pulverização das suspensões de células bacterianas contendo $10^{8} \mathrm{UFC} / \mathrm{ml}\left(\mathrm{A}_{570}=0,4\right)$ em folhas de videiras 'Red Globe' sadias com 100 dias, submetidas à pré e póstratamento em câmara úmida por $48 \mathrm{~h}$.

\section{Preservação de Xanthomonas campestris pv. viticola}

No estudo de preservação das estirpes Xcv1 e UnB1216 foram comparados os métodos de água destilada esterilizada, dessecação em papel de filtro, folhas herborizadas e repicagens periódicas, durante 12 meses com avaliações mensais. A eficiência de cada método de preservação foi avaliada com base na recuperação da bactéria e na manutenção da patogenicidade

No método de água destilada esterilizada (Pereira et al., 1970), as estirpes foram cultivadas em tubos contendo meio NYDA (dextrose 10, extrato de carne 3, extrato de levedura 5, ágar $18 \mathrm{~g} / \mathrm{l}$ de água destilada) por $48 \mathrm{~h}$. Uma alíquota, correspondente a uma "alçada" do crescimento bacteriano foi transferida para tubos plásticos de criogenia (2,0 ml), contendo 1,0 $\mathrm{ml}$ de água destilada esterilizada, sendo armazenados em condições de laboratório $\left(25 \pm 2{ }^{\circ} \mathrm{C}\right)$. A cada avaliação, uma alçada de cada estirpe foi plaqueada em meio NYDA pelo método de estrias, com quatro repetições.

O método de dessecação em papel de filtro, idealizado por Bassell et al. (Kirsop, 1991), foi realizado conforme Takatsu (1980). Suspensões densas em peptona-gelatina e dextrose foram preparadas a partir de culturas com dois a quatro dias. Tiras de papel de filtro foram embebidas com a suspensão, secas em placas de Petri contendo sílica gel e armazenadas em envelopes de papel alumínio no interior de vidros contendo sílica gel, em geladeira. A cada avaliação, quatro fitas de papel de filtro contendo cada estirpe, uma de cada pacote da preservação, foram plaqueadas em NYDA.

$\mathrm{Na}$ preservação em folhas herborizadas, folhas de videira 'Red Globe' com 100 dias, submetidas à pré e póstratamento em câmara úmida por 48 h, foram inoculadas por pulverização sem ferimento, com suspensões de células bacterianas cultivadas em tubos contendo NYDA por $48 \mathrm{~h}$ a $28{ }^{\circ} \mathrm{C}$. Após 12 dias de incubação em casa de vegetação, as folhas com sintomas foram coletadas, herborizadas por oito dias, em grades de madeira, entre folhas de jornal, a temperatura ambiente e colocadas em envelopes de papel, os quais foram armazenados em condições de laboratório. A cada avaliação, realizou-se o isolamento do patógeno a partir de uma lesão de cada folha, no total de quatro folhas para cada estirpe.

No método de repicagens periódicas, as estirpes foram cultivadas em tubos de ensaio com meio NYDA por $48 \mathrm{~h} \mathrm{e}$ conservadas a $4{ }^{\circ} \mathrm{C}$. A cada avaliação, as estirpes foram repicadas para novos tubos com NYDA com quatro repetições.

Em todos os métodos de preservação avaliados, a viabilidade da estirpe foi demonstrada pela recuperação de crescimento bacteriano em meio NYDA a $28{ }^{\circ} \mathrm{C}$ por $48 \mathrm{~h}$. Nos casos de crescimento positivo, avaliou-se a patogenicidade inoculando-se, por pulverização, as suspensões bacterianas $\left(10^{8} \mathrm{UFC} / \mathrm{ml}\right)$ em cinco folhas de mudas de videira 'Red Globe', submetidas a pré e pós-tratamento em câmara úmida por 48 h e mantidas em casa de vegetação. A incidência (porcentagem de folhas com sintomas) da doença foi avaliada aos 35 dias. Com os dados de incidência obtidos para cada método de preservação, com quatro repetições, ao longo de 12 meses, calculou-se a área abaixo da curva da incidência da doença AACID $=\Sigma\left(\mathrm{y}_{\mathrm{i}}+\mathrm{y}_{\mathrm{i}+1}\right) / 2 . \mathrm{d}_{\mathrm{ti}}$, onde $\mathrm{y}_{\mathrm{i}}$ e $\mathrm{y}_{\mathrm{i}+1}$ são os valores de incidência observados em duas avaliações consecutivas e $\mathrm{d}_{\mathrm{ti}}$, o intervalo entre as avaliações) (Shanner \& Finney, 1977). Os dados obtidos foram submetidos à análise de variância e as médias comparadas pelo teste de Tukey $(\mathrm{P}=0,01)$. O delineamento experimental foi inteiramente casualizado em arranjo fatorial $2 \times 4$, sendo duas estirpes do patógeno e quatro métodos de preservação. Foram utilizadas quatro repetições para cada método de preservação.

Crescimento de $X$. campestris pv. viticola em meio de cultura variando temperatura, $\mathrm{pH}$ e concentração de $\mathrm{NaCl}$ Em três diferentes experimentos, o crescimento das estirpes Xcv1 e UnB 1216 foi avaliado em meio de cultura líquido NYD, com incubação em estufa tipo B.O.D. (Biochemistry Oxygen Demand) às temperaturas 0, 5, 10, $15,20,25,27,28,29,30,35,40$ e $45^{\circ} \mathrm{C}$; em meio NYD com níveis de $\mathrm{pH}$ ajustados (com $\mathrm{HCl}$ e $\mathrm{KOH}$ a $1 \mathrm{M}$ ) para 5,0-9,0 com intervalos de 0,5 e em meio Caldo Nutritivo 
suplementado com $\mathrm{NaCl}$ a 1, 2, 3, 4, 5, 6 e 7\%. Alíquotas de $0,1 \mathrm{ml}$ das suspensões bacterianas foram depositadas em tubos de ensaio contendo 4,9 $\mathrm{ml}$ dos diferentes meios. No estudo do efeito dos níveis de $\mathrm{pH}$ e concentrações de $\mathrm{NaCl}$, os tubos foram mantidos em B.O.D., à $29{ }^{\circ} \mathrm{C}$. O delineamento experimental foi inteiramente casualizado com cinco repetições, sendo cada repetição constituída por um tubo de ensaio.

Após 48 h de incubação, o crescimento de Xcv1 e UnB1216 nas diferentes temperaturas, níveis de $\mathrm{pH}$ e concentrações de $\mathrm{NaCl}$ foi avaliado em fotocolorímetro Analyser $500 \mathrm{M}$ a $570 \mathrm{~nm}$, lendo-se a absorvância das suspensões. Os dados foram plotados em gráficos e submetidos à análise de regressão não linear para selecionar os modelos com os melhores ajustes às curvas de crescimento, com base no coeficiente de determinação $\left(\mathrm{R}^{2}\right)$ e no quadrado médio do resíduo.

Não houve diferença significativa $(\mathrm{P}=0,01)$ entre as estirpes testadas, tanto em relação à viabilidade quanto a patogenicidade, motivo pelo qual foram analisadas conjuntamente.

A viabilidade das estirpes preservadas pelos métodos de dessecação em papel de filtro e água destilada esterilizada foi de $100 \%$ até os 11 meses de observação, havendo aos 12 meses uma redução para 80\%. Araújo (2002) observou que o primeiro método possibilitou uma viabilidade constante de $100 \%$, durante seis meses, para estirpes de Acidovorax avenae subsp. citrulli (Schaad et al.) Willems et al. No entanto, quando Araújo (2002) utilizou o método de água de torneira esterilizada, notou que as estirpes perderam a viabilidade no decorrer das avaliações, não sendo possível recuperá-las após seis meses. Contudo, o método da água de torneira esterilizada tem sido usado com sucesso para preservação de bactérias Gram-negativas, inclusive Ralstonia solanacearum (Smith) Yabuuchi et al. (Romeiro, 2001) e Xcv (Araujo, 2001). O método de dessecação em papel de filtro pode ser utilizado para manutenção de bactérias por períodos de até 12 anos (Mariano \& Assis, 2005; Romeiro, 2001). Culturas de Pseudomonas cichorii (Swingle) Stapp, P. syringae pv. glycinea (Coerper) Young et al. e P. syringae pv. tabaci (Wolf \& Foster) Young et al. foram recuperadas com 60 a $80 \%$ de eficiência a partir deste método (Takatsu, 1980; 1994).

No método de repicagens periódicas, não se obteve crescimento da bactéria já aos 30 dias, o que o torna inviável para a preservação de Xcv. Culturas bacterianas preservadas por este método perdem constantemente a viabilidade e a estabilidade de características culturais, bioquímicas ou fisiológicas incluindo a patogenicidade, principalmente com a frequiência das subculturas (Pereira et al., 1970; Snell, 1991). Este intervalo entre repicagens constitui um dos problemas deste método, pois a meia-vida de culturas preservadas pode variar de dias a meses, em função da espécie (Romeiro, 2001).

No método de folhas herborizadas, observou-se nos três primeiros meses uma viabilidade de $100 \%$ das estirpes, embora no quarto e quinto meses houvesse uma redução para $80 \%$ e a partir do sexto mês, não puderam mais ser recuperadas. Já Araújo (2002) observou grande oscilação na porcentagem de recuperação pelo reisolamento, atribuída ao fato de que folhas diferentes foram utilizadas a cada amostragem, e que o material herborizado foi conservado à temperatura ambiente. Romeiro (2001) indica este método como viável para a maioria das bactérias fitopatogênicas e Ferreira \& Romeiro (1986) preservaram a viabilidade e patogenicidade de $P$. syringae pv. glycinea por nove anos. Os resultados obtidos neste trabalho sugerem que $\mathrm{Xcv}$ pode sobreviver em restos de cultura, servindo como fonte de inóculo primário para novos ciclos da cultura, dentro do parreiral.

Entre os métodos de preservação de Xcv, a dessecação em papel de filtro e a água destilada esterilizada propiciaram os maiores valores de AACID, sem diferir significativamente $(\mathrm{P}=0,01)$ entre si (Tabela 1$)$. Isto significa que a patogenicidade das estirpes foi mantida durante os 12 meses de avaliação. Já no método de folhas herborizadas houve grande redução da patogenicidade com o decorrer do tempo, enquanto que no de repicagens periódicas, houve perda de viabilidade e patogenicidade a partir do primeiro mês de preservação.

$\mathrm{O}$ crescimento de Xcv foi observado no intervalo de 5 até $35^{\circ} \mathrm{C}$ (Figura 1A), enquanto que um crescimento ótimo foi observado de 27 a $29^{\circ} \mathrm{C}$. Xcv não cresceu a zero e $40^{\circ} \mathrm{C}$. $\mathrm{O}$ modelo cúbico $\mathrm{Y}=\mathrm{a}+\mathrm{bx}+\mathrm{cx}^{2}+\mathrm{dx}^{3}$ apresentou um bom ajuste com $\mathrm{R}^{2}$ de $87,8 \%$. Araujo (2001) relatou temperatura máxima de $36{ }^{\circ} \mathrm{C}$ para o crescimento de Xcv e Malavolta et al. (1999) confirmaram crescimento de $\mathrm{Xcv}$ a $36{ }^{\circ} \mathrm{C}$, mas não a $41^{\circ} \mathrm{C}$. A temperatura é um dos fatores mais importantes do meio, pois influencia a absorção de nutrientes, crescimento e a sobrevivência dos organismos, determinando, de modo geral, a velocidade das reações metabólicas, por atuar na atividade enzimática (Barbosa \& Torres, 1999).

Verificou-se que as duas estirpes de Xcv cresceram numa ampla faixa de pH: 5,0 a 9,0 (Figura 1B). O modelo cúbico $\mathrm{Y}=\mathrm{a}+\mathrm{bx}+\mathrm{cx}^{2}+\mathrm{dx}^{3}$ apresentou um bom ajuste com $\mathrm{R}^{2}$ de $90 \%$. O pH ótimo para o crescimento desta bactéria foi

TABELA 1 - Métodos de preservação das estirpes Xcv1 e UnB1216 de Xanthomonas campestris pv. viticola avaliados pela área abaixo da curva da incidência da doença (AACID), durante 12 meses

\begin{tabular}{lr}
\hline \hline Método de preservação & AACID $^{\mathbf{1}}$ \\
\hline Dessecação em papel de filtro & $1097^{2} \mathrm{a}$ \\
Água de stilada esterilizada & $1097 \quad \mathrm{a}$ \\
Folhas herborizadas & $2257 \quad \mathrm{~b}$ \\
Repicagens periódicas & $0 \quad \mathrm{c}$ \\
\hline
\end{tabular}

${ }^{\text {I} C a l c u l a d a ~ c o n f o r m e ~ S h a n n e r ~ \& ~ F i n n e y ~(1977), ~ u t i l i z a n d o ~ o s ~ d a d o s ~ m e n s a i s ~}$ de incidência da doença

${ }^{2}$ Média de oito repetições. Médias seguidas pela mesma letra na vertical não diferem entre si pelo teste de Tukey $(\mathrm{P}=0,01)$ 


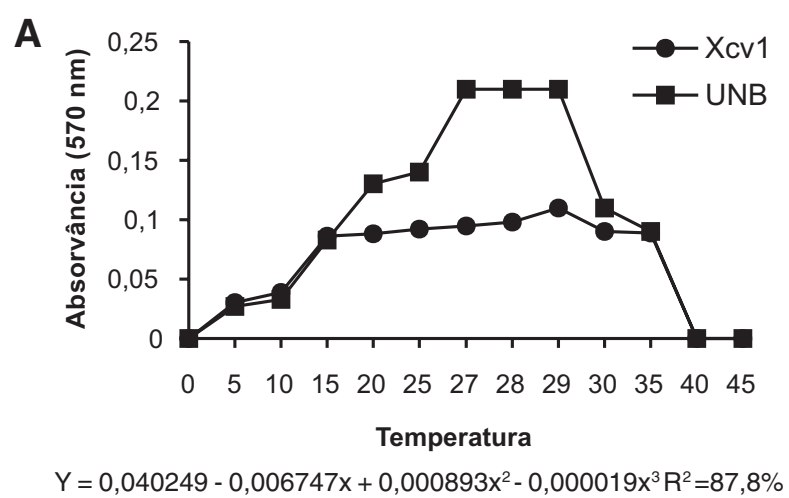

B

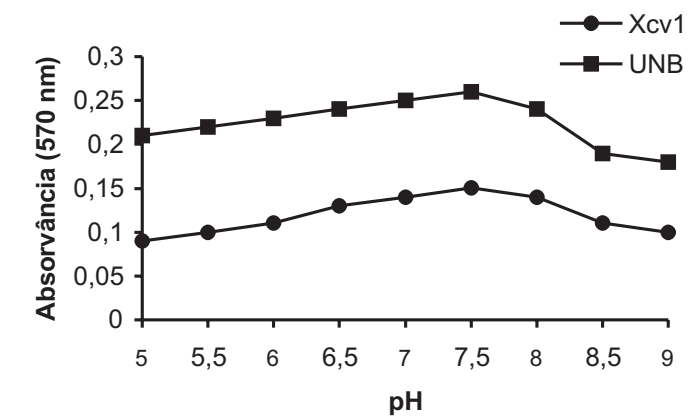

$Y=0,562100-0,267626 x+0,052619 x^{2}-0,003131 x^{3} R^{2}=90,0 \%$

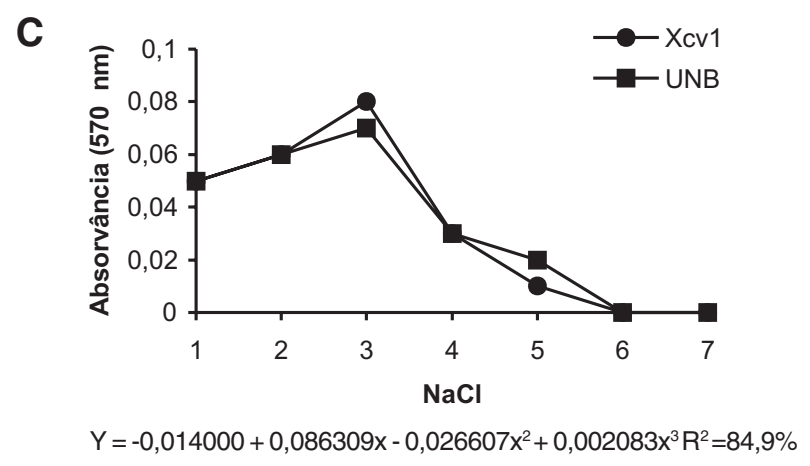

FIG. 1 - Crescimento das estirpes Xcv1 e UnB1216 de Xanthomonas campestris pv. viticola em diferentes temperaturas de incubação (A), níveis de $\mathrm{pH}$ (B) e concentrações de $\mathrm{NaCl}$ (C), respectivamente nos meios de cultura NYD, NYD e caldo nutritivo.

7,5. Existe uma variação considerável nos valores mínimos, ótimos e máximos de $\mathrm{pH}$ para o crescimento de gêneros de bactérias, mas a maioria está compreendida na faixa de $\mathrm{pH}$ mínimo variando de 4,5 a 5,0 e máximo de 8,0 a 8,5, sendo o pH ótimo entre 6,5 a 7,5 (Oginsky \& Umbreit, 1959). Acidovorax avenae subsp. citrulli requer $\mathrm{pH}$ próximo à neutralidade para maior crescimento (Cavalcanti et al., 2005).

As duas estirpes de $\mathrm{Xcv}$ cresceram similarmente nos meios contendo de 1 a $5 \%$ de $\mathrm{NaCl}$ (Figura 1C). O crescimento de Xcv decresceu a partir de 3,0\% de $\mathrm{NaCl}$, sendo nulo à $6,0 \%$. O modelo cúbico $\mathrm{Y}=\mathrm{a}+\mathrm{bx}+\mathrm{cx}^{2}+\mathrm{dx}^{3}$ apresentou um bom ajuste com $\mathrm{R}^{2}$ de $84,9 \%$. Altas concentrações de $\mathrm{NaCl}$ tornam o ambiente hipertônico. Nessas condições ocorre a perda da água da célula, através da membrana plasmática, com conseqüente inibição do crescimento (Tortora et al., 2002). Bactérias fitopatogênicas podem tolerar diferentes concentrações de $\mathrm{NaCl}$ (Mariano et al., 2005). Cavalcanti et al. (2005) também verificaram a ausência de crescimento de A. avenae subsp. citrulli nas concentrações de 6 e $7 \%$ de $\mathrm{NaCl}$.

\section{REFERÊNCIAS BIBLIOGRÁFICAS}

ARAÚJO, D.V. Métodos de inoculação e preservação de Acidovorax avenae subsp. citrulli e sobrevivência em sementes de melão. (Dissertação de Mestrado em Fitossanidade). Recife. Universidade Federal Rural de Pernambuco. 2002.

ARAUJO, J.S.P. Perfil epidemiológico e subsídios para o controle de Xanthomonas campestris pv. viticola (Nayudu) Dye, agente do cancro bacteriano da videira (Vitis vinifera) no Brasil. (Tese de Doutorado em Fitotecnia). Rio de Janeiro. Universidade Federal Rural do Rio de Janeiro. 2001.

BARBOSA, H.R. \& TORRES, B.B. Nutrição e metabolismo bacterianos. In: Trabulsi, L.R., Althertum, F., Gompertz, O.F. \& Candeias, N.J.A.N. (Eds). Microbiologia. $3^{\mathrm{a}}$ ed. São Paulo. Atheneu. 1999. pp.25-54.

CAVALCANTI, M.T. SILVEIRA, E.B., MARIANO, R.L.R. \& VIANA, I.O. Crescimento de Acidovorax avenae subsp. citrulli sob diferentes temperaturas, $\mathrm{pH}$, concentrações de $\mathrm{NaCl}$ e fontes de carbono. Ciência Rural 35. 2005. (no prelo)

FERREIRA, L.P. \& ROMEIRO, R.S. Ampliação de cultivares da série diferenciadora de raças fisiológicas de Pseudomonas syringae pv. glycinea em soja. Fitopatologia Brasileira 11:335. 1986 (Resumo).

KIRSOP, B.E. Maintenance of yeasts. In: Kirsop, B.E. \& Doyle, A. (Eds.) Maintenance of Microorganisms and Cultured Cells. A Manual of Laboratory Methods. $2^{\text {nd }}$ ed. London. Academic Press. 1991. pp.161-182.

MALAVOLTA JR., V.A., ALMEIDA, I.M.G., SUGIMORI, M.H., RIBEIRO, I.J.A, RODRIGUES NETO, J., PIRES, E.J.P. \& NOGUEIRA, E.M.C. Ocorrência de Xanthomonas campestris pv. viticola em videira no Brasil. Summa Phytopathologica 25:262-264. 1999.

MARIANO, R.L.R. \& ASSIS, S.M.P. Preservação de bactérias fitopatogênicas. In: Mariano, R.L.R. \& Silveira, E.B. (Coords.). Manual de Práticas em Fitobacteriologia. $2^{\text {a }}$ ed. Recife. UFRPE. 2005. pp.35-45.

MARIANO, R.L.R., SILVEIRA, E.B., ASSIS, S.M.P. \& GOMES, A.M.A. Identificação de bactérias fitopatogênicas. In: Mariano, R.L.R. \& Silveira, E.B. (Coords.). Manual de Práticas em Fitobacteriologia. 2a . ed. Recife. UFRPE. 2005. pp.67-111.

OGINSKY, E. L. \& UMBREIT, W.W. An Introduction to Bacterial Physiology. $2^{\text {nd }}$ ed. San Francisco. W.H. Freeman and Company. 1959.

PEREIRA, A.L.G., ZAGATTO, A.G. \& FIGUEIREDO, M.B. Preservação e virulência de bactérias mantidas em água destilada. 
O Biológico 36:311-314. 1970.

ROMEIRO, R.S. Preservação de bactérias fitopatogênicas. In: Romeiro, R.S. (Ed.) Métodos em Bacteriologia de Plantas. Viçosa. UFV. 2001. pp.87-96.

SHANER, G. \& FINNEY, R.E. The effect of nitrogen fertilization on the expression of slow-mildewing resistance in knox wheat. Phytopathology 15:1051-1056. 1977.

SNELL, J.J.S. General introduction to maintenance methods. In: Kirsop, B.E. \& Doyle, A. (Eds.) Maintenance of Microorganisms and Cultured Cells. A Manual of Laboratory
Methods. $2^{\text {nd }}$ ed. London. Academic Press. 1991. pp.21-30.

TAKATSU, A. Preservação das bactérias fitopatogênicas pelo método de dessecação. Fitopatologia Brasileira 5:461. 1980 (Resumo).

TAKATSU, A. Coleção de bactérias fitopatogênicas preservadas pelo método de dessecação em tirinhas de papel. Informações de dez anos. Fitopatologia Brasileira 5:315. 1994 (Resumo).

TORTORA, G.J., FUNKE, B.R. \& CASE, C.L. Microbiologia. Porto Alegre. Artes Médicas. 2002. 